\title{
Fertility of male adult rats submitted to forced swimming stress
}

G.Z. Mingoti, R.N. Pereira and C.M.R. Monteiro
Departamento de Produção e Saúde Animal, Medicina Veterinária, Universidade Estadual Paulista, Araçatuba, SP, Brasil

\section{Correspondence}

G.Z. Mingoti

Medicina Veterinária, UNESP

Rua Clóvis Pestana, 793

16050-680 Araçatuba, SP

Brasil

Fax: +55-18-622-6487

E-mail: gmingoti@fmva.unesp.br

Presented at the XVII Annual Meeting of the Federação de Sociedades de Biologia Experimental, Salvador, BA, Brazil, August 28-31, 2002.

Publication supported by FAPESP. R.N. Pereira was a scientific initiation student.

Received April 11, 2002 Accepted February 17, 2003

\begin{abstract}
We investigated whether stress interferes with fertility during adulthood. Male Wistar rats (weighing $220 \mathrm{~g}$ in the beginning of the experiment) were forced to swim for $3 \mathrm{~min}$ in water at $32^{\circ} \mathrm{C}$ daily for 15 days. Stress was assessed by the hot-plate test after the last stressing session. To assess fertility, control and stressed males $(\mathrm{N}=15$ per group) were mated with sexually mature normal females. Males were sacrificed after copulation. Stress caused by forced swimming was demonstrated by a significant increase in the latency of the pain response in the hot-plate test $(14.6 \pm 1.25 \mathrm{~s}$ for control males $v s 26.0$ $\pm 1.53 \mathrm{~s}$ for stressed males, $\mathrm{P}=0.0004)$. No changes were observed in body weight, testicular weight, seminal vesicle weight, ventral prostate weight or gross histological features of the testes of stressed males. Similarly, no changes were observed in fertility rate, measured by counting live fetuses in the uterus of normal females mated with control and stressed males; no dead or incompletely developed fetuses were observed in the uterus of either group. In contrast, there was a statistically significant decrease in spermatid production demonstrated by histometric evaluation (154.96 \pm 5.41 vs $127.02 \pm 3.95$ spermatids per tubular section for control and stressed rats, respectively, $\mathrm{P}=$ $0.001)$. These data demonstrate that 15 days of forced swimming stress applied to adult male rats did not impair fertility, but significantly decreased spermatid production. This suggests that the effect of stress on fertility should not be assessed before at least the time required for one cycle of spermatogenesis.
\end{abstract}

Key words

- Forced swimming stress

- Male

- Fertility

- Rat

- Spermatogonia
The testes carry out spermatogenesis and steroidogenesis in distinct compartments of the organ, i.e., seminiferous tubules and the interstitial space, respectively (1). Leydig cells, under the stimulus of luteinizing hormone (LH), secrete testosterone that is required by Sertoli cells to support spermatogenesis during all of its phases (2).

A variety of stressors such as hyperthermia, microorganisms, and exposure to heavy metals inhibit male reproductive functions and/or spermatogenesis (1). Similar effects were observed after application of the stressful stimuli such as prolonged immobilization (3). It has been established that activation of the hypothalamic-pituitary-adrenal axis in response to prolonged stress may inhibit male reproductive functions through a depression of the hypothalamic-pituitary-testicular axis (4). Other studies have revealed that mechan- 
isms leading to a reduced population of germ cells involve apoptosis, with subsequent testicular atrophy (5).

Different forms of stress can produce potent analgesia. These stress-induced antinociceptive effects are mediated by complex endogenous antinociceptive systems (6) and the differential activation of opioid and nonopioid mechanisms of analgesia by stress appears to depend upon the characteristics of the stressor and pain test employed (7). For example, in swim stress-induced analgesia, altering the temperature of the water influences the extent of the involvement of opioid and non-opioid mechanisms (8). A 3min swim in $32^{\circ} \mathrm{C}$ water produces a mixed opioid and non-opioid analgesia measured by the hot-plate test (7). It is well known that reproductive functions can be inhibited by opioid mechanisms because opioids strongly modulate gonadotropin and neurohypophyseal hormone secretion during animal reproduction (9). For example, Met-enkephalin inhibits LH secretion in males and $\beta$-endorphin and Leu-enkephalin can modify LH secretion (9).

The purpose of the present study was to determine whether forced swimming stress applied to adult male rats affects fertility during adulthood.

Adult male Wistar rats, weighing $220 \mathrm{~g}$ in the beginning of the experiment, were housed under controlled environmental conditions, with free access to laboratory chow and tap water. Animals were housed individually in metabolic cages for the determination of daily ingestion of food and water. Animals were divided into two groups of 15 each. Controls remained undisturbed in their cages and the animals of the stressed group were submitted to forced swimming for $3 \mathrm{~min}$ in water at $32^{\circ} \mathrm{C}$ daily for 15 days. Stress was assessed by the hot-plate test after the last stressing session. In the hot-plate test, the plate temperature was $52^{\circ} \mathrm{C}$ and the maximal cut-off time was $60 \mathrm{~s}$. The latency time for hind paw licking after exposure to the hot- plate surface was measured and the increase in relation to control was considered to be an index of the antinociceptive effect.

Stressed and control males were mated with sexually mature normal females who had presented at least three regular cycles, confirmed by analysis of daily vaginal smears. Females in the proestrus stage in the morning were mated with males overnight ( $1 \mathrm{fe}-$ male per 1 male) and the presence of spermatozoa in the vaginal smear on the next morning was considered to indicate the occurrence of copulation. Females were autopsied on day 20 of pregnancy and their uteri were examined for number of live fetuses; no dead or incompletely developed fetuses were observed in the uterus of either group.

Males were sacrificed after copulation and the testes, seminal vesicle and ventral prostate were removed, weighed and fixed in Bouin's solution for $24 \mathrm{~h}$. Six-micrometer thick paraffin sections were stained with hematoxylin and eosin for histological and histometric analysis. Spermatid production was estimated by the amount of round spermatids in the maturation phase (stages I to VII of spermatogenesis, identified according to Ref. 10) counted in 10 seminiferous tubule cross-sections per animal.

Data are reported as means \pm SEM. The statistical significance of the difference between the control and stressed groups was determined by the unpaired $t$-test. Probabilities of less than $5 \%(\mathrm{P}<0.05)$ were considered to be significant.

There was no difference between control and stressed rats in body weight (303.37 \pm 15.62 vs $335.19 \pm 11.53 \mathrm{~g}$, respectively), testicle weight $(1.56 \pm 0.07$ vs $1.60 \pm 0.05 \mathrm{~g}$, respectively), seminal vesicle weight $(0.39 \pm$ 0.02 vs $0.45 \pm 0.03 \mathrm{~g}$, respectively), ventral prostate weight $(0.32 \pm 0.02$ vs $0.36 \pm 0.04 \mathrm{~g}$, respectively) or gross histological features. However, a statistically significant decrease in spermatid production was demonstrated by histometric methods: $154.96 \pm 5.41$ and 
$127.02 \pm 3.95$ spermatids per tubular section for control and stressed rats, respectively (Table 1). No difference in food or water intake was observed between groups during the experiment (data not shown).

In the hot-plate test, a 3-min swim at $32^{\circ} \mathrm{C}$ significantly prolonged the latency time for hind paw licking (14.6 \pm 1.25 and $26.0 \pm$ $1.53 \mathrm{~s}$ for control and stressed rats, respectively, $\mathrm{P}=0.0004$; Table 1).

Data for females submitted to autopsy on day 20 of pregnancy were used to estimate male fertility rates. No difference $(\mathrm{P}>0.05)$ was observed in the number of live fetuses per uterus of females mated with control or with stressed males $(11.09 \pm 1.3 v s$ and 10.3 \pm 1.41 live fetuses, respectively; Table 1).

The present data demonstrate that forced swimming causes stress, as confirmed by a significant rise in latency time for the pain response in the hot-plate test. As mentioned above, others have shown that a 3-min swim in $32^{\circ} \mathrm{C}$ water produces a mixed opioid/nonopioid analgesia when animals were submitted to the hot-plate test (7). Opiates are likely to play a role in the decreased gonadotropin secretion observed during both acute and chronic stress, having a major impact on the regulation of amplitude and frequency of the pulsatile pattern of LH secretion $(11,12)$. Testosterone released from the Leydig cells under the influence of LH and follicle-stimulating hormone are the key regulators of the spermatogenic function of the testis and it is clear that both hormones are needed to initiate and maintain the process of spermatogenesis (1). There is a decrease in testosterone secretion in male rats exposed to immobilization-induced stress $(4,10,13,14)$, a fact attributed to reduced LH concentration (15). Testosterone is crucial for the differentiation of round to elongated spermatids, and the specific effect of testosterone during spermiogenesis is on the conversion of round spermatids from stage VII to stage VIII of the spermatogenic cycle (2). When intratesticular testosterone was reduced, few stage
VII round spermatids progressed to stage VIII (2).

On the basis of these considerations, we analyzed the effect of forced swimming stress on the number of spermatids in the seminiferous tubules. We showed that forced swimming stress caused a significant decrease in the number of spermatids in seminiferous tubules. This result supports literature data showing the inhibition of spermatogenesis in response to various stressors $(1,3,10)$. Spermatogenesis in the rat is divided into 14 stages or cell associations (16) and the complete sequence of these stages constitutes one cycle of the seminiferous epithelium, which lasts 48 to 53 days in the rat (16). Although the response of plasma testosterone concentration to stressful stimuli was not measured in the present study, literature data strongly support the hypothesis that the decrease in circulating testosterone levels of stressed males can be responsible for depressing spermatogenesis $(10,13,15)$. In addition, stress may activate the hypothalamicpituitary-adrenal axis (4) and the roles of corticotropin-releasing hormone, adrenocorticotropin (ACTH) and the adrenal glucocorticoids in the regulation of gonadotropinreleasing hormone $(\mathrm{GnRH})$ pulse generator activity have also been studied extensively

Table 1. Effect of forced swimming stress on some adult male reproductive parameters.

\begin{tabular}{lrr}
\hline & Control rats & $\begin{array}{r}\text { Forced swimming- } \\
\text { stressed rats }\end{array}$ \\
\hline Latency time for hind paw licking (s) & $14.6 \pm 1.25$ & $26.0 \pm 1.53^{*}$ \\
Body weight (g) & $303.37 \pm 15.62$ & $335.19 \pm 11.53$ \\
Testicle weight (g) & $1.56 \pm 0.07$ & $1.60 \pm 0.05$ \\
Seminal vesicle weight (g) & $0.39 \pm 0.02$ & $0.45 \pm 0.03$ \\
Ventral prostate weight (g) & $0.32 \pm 0.02$ & $0.36 \pm 0.04$ \\
Spermatids/tubular section & $154.96 \pm 5.41$ & $127.02 \pm 3.95^{*}$ \\
Live fetuses/uterus & $11.09 \pm 1.3$ & $10.3 \pm 1.41$
\end{tabular}

The forced swimming-stressed rats were submitted to 3-min daily forced swimming for 15 days. The significantly increased latency time for hind paw licking in the hotplate test confirmed that the rats were stressed. Data are reported as means \pm SEM for 15 rats.

${ }^{*} \mathrm{P} \leq 0.05$ compared to control (unpaired $t$-test). 
(14). However, the exact site where ACTH, or even corticosteroids, exert their effect on the reproductive process is still not known. A wide variety of mechanisms have been proposed, including the activation of opioid pathways, a steroid-mediated decrease in the ability of the pituitary to respond to GnRH resulting in a fall in $\mathrm{LH}$ production, and a direct or indirect effect of ACTH and/or corticosteroids on the gonads $(4,14)$. Previous studies have demonstrated a direct effect of glucocorticoids on testicular LH receptors and on steroidogenesis, demonstrating the existence of regulation of testicular function by the adrenals (17). As a consequence of the reduction in LH receptors, stress causes a reduction of testosterone secretion $(4,14)$. Thus, the stressful stimulus may interfere both with endocrine and local factors, disturbing spermatid production.

On the other hand, the present data demonstrated no change in testicular weight or gross histological features after 15 days of forced swimming. Similarly, no difference was observed in the fertility of control or stressed males, as indicated by the similar number of live fetuses found in the uterus of autopsied females. The data demonstrated that 15 days of forced swimming stress applied to adult male rats did not immediately impair fertility, but significantly decreased spermatid production. The normal fertility exhibited by stressed males may be explained by the fact that forced swimming lasted 15 days, a period shorter than the 48- to 53-day duration of one cycle of the seminiferous epithelium. Previous studies have shown that long-term testosterone suppression led to reduced spermatogonial and spermatocyte production, and that losses during these earlier stages of germ cell development led to reduction in the spermatid population (18). When intratesticular testosterone was suppressed for 11 weeks, the conversion of round spermatids from stage VII to stage VIII was markedly suppressed and elongated spermatids were not detected. However, round spermatid conversion was not affected until 3 weeks of testosterone withdrawal, perhaps because of the persistence of androgen action for several weeks after the reduction in testicular testosterone levels (18). Since stress reduces testosterone secretion $(3,4,14)$, it is possible that impairment of male reproductive function and/or spermatogenesis is due to the reduced testosterone levels. Our data suggest that short-term forced swimming stress leads to a reduction in the round spermatid population, but the conversion of preexisting round spermatids was apparently unaffected, as indicated by normal fertility. Thus, the present data suggest that the effects of stress on fertility should be better assessed after the period of time necessary to complete an entire cycle of the seminiferous epithelium, i.e., between 48 and 53 days in the rat (16), or at least after the period of time necessary for spermatids to mature.

\section{References}

1. Ozawa N, Goda N, Makino N, Yamaguchi T, Yoshimura Y \& Suematsu M (2002). Leydig cell-derived heme oxygenase-1 regulates apoptosis of premeiotic germ cells in response to stress. Journal of Clinical Investigation, 109: 457-467.

2. O'Donnell L, McLachlan RI, Wreford NG \& Robertson DM (1994). Testosterone promotes the conversion of round spermatids between stages VII and VIII of the rat spermatogenic cycle. Endocrinology, 135: 2608-2614

3. Almeida SA, Kempinas WG \& Lamano Carvalho TL (2000). Sexual behavior and fertility of male rats submitted to prolonged immobilization-induced stress. Brazilian Journal of Medical and Biological
Research, 33: 1105-1109.

4. Rivier C \& Rivest S (1991). Effect of stress on the activity of the hypothalamic-pituitary-gonadal axis: peripheral and central mechanism. Biology of Reproduction, 45: 523-532.

5. Richburg JH (2000). The relevance of spontaneous- and chemicallyinduced alterations in testicular germ cell apoptosis to toxicology. Toxicology Letters, 112-113: 79-86.

6. Lewis JW, Cannon JT \& Liebeskind JC (1980). Opioid and nonopioid mechanism of stress analgesia. Science, 208: 623-625.

7. Vaccarino AL, Marek P, Sternberg W \& Liebeskind JC (1992). NMDA receptor antagonist MK-801 blocks non-opioid stress-induced anal- 
gesia in the formalin test. Pain, 50: 119-123.

8. Izumi R, Takahashi M \& Kaneto H (1983). Involvement of different mechanisms, opioid and non-opioid forms, in the analgesia induced by footshock (FS) and immobilized-water immersion (IW) stress. Japanese Journal of Pharmacology, 33: 1104-1106.

9. Parvizi N (2000). Neuroendocrine regulation of gonadotropins in the male and the female. Animal Reproduction Science, 60-61: 31-47.

10. Almeida SA, Petenusci SO, Anselmo-Franci JA, Rosa-e-Silva AAM \& Lamano Carvalho TL (1998). Chronic intermittent immobilization of male rats throughout sexual development: a stress protocol. Brazilian Journal of Medical and Biological Research, 31: 1443-1448.

11. Van Vugt DA, Sylvester PW, Aylsworth CF \& Meites J (1982). Counteraction of gonadal steroid inhibition of LH by naloxone. Neuroendocrinology, 34: 274-278.

12. Kinoshita F, Nakai I, Katakami H, Kato G, Yajima H \& Imura H (1980). Effect of $B$ endorphin on pulsatile luteinizing hormone release in conscious castrated rats. Life Sciences, 27: 843-846.

13. López-Calderón A, Ariznavarreta C, González-Quijano MI, Tres- guerres JAF \& Calderón MD (1991). Stress induced changes in testis function. Journal of Steroid Biochemistry and Molecular Biology, 40: 473-479.

14. Rivier C \& Vale W (1984). Influence of CRF on reproductive functions in the rat. Endocrinology, 114: 914-921.

15. Demura R, Suzuki T, Nakamura S, Komatsu H, Odagiri E \& Demura H (1989). Effect of immobilisation stress on testosterone and inhibin in male rats. Journal of Andrology, 10: 210-213.

16. Clermont Y, Le Blond CP \& Messier B (1959). Durée du cycle d'epithelium seminal du rat. Archives d'Anatomie Microscopique et de Morphologie Experimentale, 48: 37-56.

17. Bambino TH \& Hsueh AJW (1981). Direct inhibitory effect of glucocorticoids upon testicular $\mathrm{LH}$ receptor and steroidogenesis in vivo and in vitro. Endocrinology, 108: 2142-2148.

18. O'Donnell L, McLachlan RI, Wreford NG, Kretser DM \& Robertson DM (1996). Testosterone withdrawal promotes stage-specific detachment of round spermatids from the rat seminiferous epithelium. Biology of Reproduction, 55: 895-901. 